\title{
Impairment of the serotonergic control of feeding in adult female rats exposed to intra-uterine malnutrition
}

\author{
Laura C. J. Pôrto ${ }^{1}$, Fátima L. C. Sardinha ${ }^{2}$, Mônica M. Telles ${ }^{1}$, Regina B. Guimarães ${ }^{1}$, \\ Kelse T. Albuquerque ${ }^{3}$, Iracema S. Andrade ${ }^{1}$, Lila M. Oyama ${ }^{3}$, Cláudia M. O. Nascimento ${ }^{1}$, \\ Oscar F. P. Santos ${ }^{4}$ and Eliane B. Ribeiro ${ }^{1 *}$ \\ ${ }^{1}$ Departamento de Fisiologia, Disciplina de Fisiologia da Nutrição, Universidade Federal de São Paulo, São Paulo, SP, Brazil \\ ${ }^{2}$ Instituto de Nutrição Josué de Castro, Universidade Federal do Rio de Janeiro, Rio de Janeiro, RJ, Brazil \\ ${ }^{3}$ Departamento de Biociências, Universidade Federal de São Paulo, Santos, SP, Brazil \\ ${ }^{4}$ Departamento de Medicina, Disciplina de Nefrologia, Universidade Federal de São Paulo, São Paulo, SP, Brazil
}

(Received 10 December 2007 - Revised 25 July 2008 - Accepted 25 July 2008 - First published online 12 September 2008)

\begin{abstract}
We have previously shown that adult female rats exposed to intra-uterine malnutrition were normophagic, although obese and resistant to insulininduced hypophagia. The present study aimed at examining aspects of another important catabolic component of energy homeostasis control, the hypothalamic serotonergic function, which inhibits feeding and stimulates energy expenditure. Pregnant dams were fed ad libitum or were restricted to $50 \%$ of ad libitum intake during the first 2 weeks of pregnancy. Control and restricted 4-month-old progeny were studied. The restricted rats had increased body adiposity with normal daily food intake but failed to respond with hypophagia to an intracerebroventricular injection of serotonin (5-hydroxytryptamine; 5-HT). Stimulation, by food ingestion, of extracellular levels of serotonin in medial hypothalamus microdialysates was more pronounced and lasted longer in the restricted than in the control rats. In the restricted group, hypothalamic levels of 5-HT $2 \mathrm{C}$ receptor protein tended to be reduced $(P=0.07)$ while the levels of $5-\mathrm{HT}_{1 \mathrm{~B}}$ receptor and serotonin transporter proteins were significantly elevated (36 and $79 \%$, respectively). In conclusion, female rats undernourished in utero had normophagic obesity as adults but had an absence of serotonininduced hypophagia and low hypothalamic levels of the 5- $\mathrm{HT}_{2 \mathrm{C}}$ receptor. Compensatory adaptations for the functional serotonergic impairment were evidenced, such as an enhanced release of serotonin in response to a meal allied to up-regulated hypothalamic 5-HT $1 \mathrm{~B}$ and transporter expression. Whether these compensations will persist in later life warrants further investigation. Moreover, it cannot be ruled out that the serotonergic component of energy expenditure was already impaired, thus contributing to the observed body-fat phenotype.
\end{abstract}

Intra-uterine malnutrition: Serotonin: Hypothalamus: Obesity: Control of feeding

The hypothalamus is the major centre of interaction of the numerous anabolic and catabolic factors involved in the control of energy balance. The serotonergic system plays a key role in these mechanisms, inhibiting food intake and stimulating energy expenditure ${ }^{(1-4)}$.

Serotonin (5-hydroxytryptamine; 5-HT) release is stimulated by the ingestion of food in hypothalamic sites related to feeding control, a finding that points to the physiological relevance of the system ${ }^{(5-10)}$. Moreover, several investigations indicate that alterations of central serotonergic activity are present in obese rodents and humans ${ }^{(6,10-12)}$ and drugs that act as serotonin receptor agonists or serotonin reuptake inhibitors are used in the treatment of obesity $(13,14)$.

Obesity, with its associated conditions, such as CVD, hypertension, insulin resistance, type 2 diabetes and the metabolic syndrome, represents nowadays a major health issue worldwide. Malnutrition during intra-uterine life has been linked to the development of obesity in later life.
The 'thrifty phenotype' hypothesis suggests that the adaptive strategies developed during the period of poor nutrient or energy delivery may become programmed, influencing the homeostatic mechanisms towards maximisation of energy uptake and storage ${ }^{(3,15)}$.

We have recently demonstrated that female rats exposed to protein-energy malnutrition during early intra-uterine life presented with non-hyperphagic obesity as adults. Evidence of a deranged central control of feeding was provided by the findings of impairment of insulin-induced hypophagia and hypothalamic signal transduction. The absence of overt hyperphagia pointed to the suggestion that adaptations took place which, at least until that point in life, were able to counterbalance the hypothalamic resistance to insulin, maintaining food intake and limiting the severity of obesity ${ }^{(16)}$.

The serotonergic system has been shown to participate in such compensatory mechanisms. For example, downregulation of serotonergic activity reportedly occurred in

Abbreviations: 5-HT, 5-hydroxytryptamine (serotonin); 5-HIAA, 5-hydroxyindoleacetic acid; ST, serotonin transporter; VMH, ventromedial hypothalamus. 
neuropeptide Y-deficient mice ${ }^{(17)}$. Moreover, the status of the serotonergic system is highly influenced by diet and a nutritional stress during gestation could affect its development, bringing consequences to the control of feeding in adulthood. Data on the effects of gestational undernutrition upon the serotonergic system are not conclusive. Prenatal protein malnutrition failed to affect serotonin and 5-hydroxyindoleacetic acid (5-HIAA) levels in various brain areas, including the hypothalamus, of adult rats ${ }^{(18)}$. Serotonin turnover increased in the hypothalamus of infant rats protein malnourished during prenatal life ${ }^{(19)}$. Contrastingly, a decreased density of serotonin binding sites has been found in the cerebral cortex and brainstem of infant rats born from dams fed only $50 \%$ of the normal nutritional intake during the whole gestation $^{(20)}$. Impairment of brain serotonergic transmission has also been seen in human newborns with intra-uterine growth restriction $^{(21)}$.

In view of the important participation of serotonin on the central control of energy homeostasis, a better knowledge of its functional status after a prenatal malnutrition is of interest. The present work aimed to contribute to this subject by assessing some aspects related to the serotonergic control of feeding in adult female rats, either control or undernourished during the first 2 weeks in utero. We assessed serotonin's ability to inhibit food intake after intracerebroventricular administration, the hypothalamic levels of the serotonin transporter (ST) and the $5-\mathrm{HT}_{1 \mathrm{~B}}$ and $5-\mathrm{HT}_{2 \mathrm{C}}$ receptor proteins, and the levels of serotonin in microdialysates of the medial hypothalamus, in response to the ingestion of food.

\section{Experimental methods}

\section{Animals and experimental design}

The Committee on Animal Research Ethics of the Federal University of São Paulo approved the procedures used in the present experiments. Virgin Wistar rats were mated and the first day of pregnancy was determined by examination of vaginal smears for the presence of sperm. Since day 1 of pregnancy, the dams were randomly assigned to be a control or a restricted dam. The control dams (n 11) were fed ad libitum throughout pregnancy and lactation. The restricted dams ( $n$ 16) were food restricted, during the first 2 weeks of pregnancy, to $50 \%$ of the intake of the control dams at the same pregnancy day. During the week 3 of pregnancy and lactation, the restricted dams were pair-fed to the control dams. On the day of delivery, the pups were adjusted to eight per dam, including both male and female pups, with a male:female ratio of 2:6. At weaning, two female pups from each litter were randomly selected and assigned to the different studies.

Upon weaning (postnatal day 21), the female offspring from control dams (control group) and from restricted dams (restricted group) were caged five per cage. Both the control and restricted rats were fed ad libitum, from weaning until age 4 months, when all data presented herein were collected. Only female offspring were used in the present study.

All animals were maintained in controlled conditions of lighting $(12 \mathrm{~h}-12 \mathrm{~h}$ light-dark cycle, lights off at 18.00 hours) and temperature $\left(24 \pm 1^{\circ} \mathrm{C}\right)$ and had free access to water throughout the experimental period. The food provided to dams and offspring consisted of standard rat chow (Nuvital
Nutrients, Columbo, PR, Brazil) containing (w/w) $4.5 \%$ fat, $23 \%$ protein and $33 \%$ carbohydrate, with $11.3 \mathrm{~kJ} / \mathrm{g}$ $(2.7 \mathrm{kcal} / \mathrm{g})$, as determined at the Bromatology Division of the Federal University of São Paulo.

\section{Carcass and blood determinations}

The control and restricted rats were decapitated after an overnight fast. Trunk blood was collected and serum stored at $-70^{\circ} \mathrm{C}$ until analysed. Insulin was assayed by RIA using a commercially available kit (DPC, Los Angeles, CA, USA) and glucose levels were determined by the glucose oxidase method (Labtest Diagnóstica, Vista Alegre, MG, Brazil).

For determination of carcass lipid content, carcasses were shaved, softened and homogenised after removal of the gastrointestinal tract ${ }^{(22)}$. Lipid was extracted from $5 \mathrm{~g}$ samples with petroleum ether and determined gravimetrically ${ }^{(23)}$.

\section{Microdialysis experiments}

The animals were anaesthetised with ketamine-xylazine $(67 / 13 \mathrm{mg} / \mathrm{kg})$ and stereotaxicaly implanted with a 21 -gauge guide cannula aimed at the right ventromedial hypothalamus (VMH) (from the bregma: anterior $-2.5 \mathrm{~mm}$, lateral $-0.6 \mathrm{~mm}$ and ventral $-7.9 \mathrm{~mm}$; Paxinos \& Watson $\left.{ }^{(24)}\right)$. The cannula was secured to the skull with screws and dental cement and the animals were individually caged thereafter.

After at least 1 week of recovery, a concentric custom-constructed microdialysis probe $(1.5 \mathrm{~mm}$ of effective membrane length) was inserted through the VMH guide and fixed to it with a small drop of dental cement. The details of probe construction have been described previously ${ }^{(6)}$. The animals were connected to a swivel system, which allowed continuous probe perfusion with artificial cerebrospinal fluid by a microperfusion pump (Carnegie Medicin, Solna, Sweden). Cerebrospinal fluid composition was: $145 \mathrm{~mm}-\mathrm{NaCl}, 2.7 \mathrm{mM}-\mathrm{KCl}$, $1.0 \mathrm{~mm}-\mathrm{MgCl}_{2}, \quad 1.2 \mathrm{mM}-\mathrm{CaCl}_{2}, \quad 2.0 \mathrm{~mm}-\mathrm{Na}_{2} \mathrm{HPO}_{4}$ (pH 7.4). Overnight perfusion was performed at $1.0 \mu \mathrm{l} / \mathrm{min}$.

On the next morning (after an overnight fast) probe flow rate was adjusted to $1.5 \mu \mathrm{l} / \mathrm{min}$ and collection of $20 \mathrm{~min}$ dialysate samples was started after at least $2 \mathrm{~h}$. Samples were collected into $10 \mu \mathrm{l} \quad 0 \cdot 5 \mathrm{M}$-perchloric acid and immediately injected into an HPLC system. Baseline samples were collected until 5-HT levels were stable; the last three samples were averaged to yield the mean baseline level (100\% value). Food pellets $(2.0 \mathrm{~g})$ were then introduced into the cages and six additional 20 min microdialysate samples were collected. The amount of food consumed was recorded every $20 \mathrm{~min}$, coinciding with the interval of microdialysate collection.

\section{High-performance liquid chromatography analysis}

Dialysate levels of 5-HT and 5-HIAA were measured by HPLC with electrochemical detection. The system (ESA Inc., Chelmsford, MA, USA) consisted of a model 580 pump with two PEEK pulse dampers in series, a $50 \mu \mathrm{l}$ Rheodyne PEEK sample loop, a $3 \mu \mathrm{m}$ MD $150 \mathrm{C}$ column, a model 5020 guard cell set at $300 \mathrm{mV}$, a model 5014B analytical cell set at -175 and $150 \mathrm{mV}$, and a model 5200A detector. The mobile phase consisted of $75 \mathrm{~mm}$-sodium phosphate, 
$1.5 \mathrm{~mm}$-octanesulfonic acid, $50 \mu \mathrm{M}$-EDTA, triethylamine $(100 \mu \mathrm{l} / \mathrm{l})$ and $10 \%(\mathrm{v} / \mathrm{v})$ acetonitrile at $\mathrm{pH} 3 \cdot 0$. The flow rate was $0.6 \mathrm{ml} / \mathrm{min}$. The detection limit for $5-\mathrm{HT}$ was $1.5 \mathrm{pg} / 50 \mu \mathrm{l}$ at a signal:noise ratio of $3: 1$.

\section{Histological analysis}

For verification of positioning of the microdialysis membranes, at the termination of the experiments all animals were deeply anaesthetised and perfused with $0.9 \%$ saline followed by $10 \%$ formalin. Brains were removed and $40 \mu \mathrm{m} \mathrm{sec-}$ tions were examined under a microscope, following staining with Cresyl violet. Only data from rats with correct membrane placements were included in the analysis.

\section{Intracerebroventricular cannula implantation and measurement of food intake}

At 1 week before reaching age 4 months, the animals were stereotaxicaly implanted with a 23-gauge guide cannula aimed at the lateral cerebral ventricle (from the bregma: anterior $-0.9 \mathrm{~mm}$, lateral $+1.6 \mathrm{~mm}$ and ventral $-2.5 \mathrm{~mm}$; Paxinos \& Watson ${ }^{(24)}$ ). The cannula was secured to the skull with screws and dental cement. The animals were individually caged and maintained with food and water ad libitum for 1 week after surgery. After this recovery period, they were fasted for $6 \mathrm{~h}$ and then intracerebroventricularly injected with either $2.0 \mu \mathrm{l}$ saline or $2.0 \mu \mathrm{l}$ saline containing $200 \mu \mathrm{g}$ serotonin (Sigma, St Louis, MO, USA). The injections were performed in the animal room, immediately before lights out. The rats were returned to their home cages and pre-weighed food cups were introduced into the cages. The amount of food consumed was determined $24 \mathrm{~h}$ later, by weighing the amount of food remaining in the cup. Measurements of food intake were corrected for spillage.

After these measurements, the placement of the intracerebroventricular cannula was examined. For this, the animals were deeply anaesthetised, received an intracerebroventricular injection of $5 \mu \mathrm{l}$ Evans blue dye, were killed by decapitation and had their brains removed for inspection of dye distribution. Only the results from animals in which the placement of the intracerebroventricular cannula was correct were included in the analysis.

\section{Immunoprecipitation and immunoblotting}

The animals were decapitated under anaesthesia (ketaminexylazine, $33 / 6.5 \mathrm{mg} / \mathrm{kg}$ ) and their hypothalami quickly removed and homogenised in $1.0 \mathrm{ml}$ solubilisation buffer $(100 \mathrm{~mm}$ 2-amino-2-hydroxymethyl-propane-1,3-diol ( $\mathrm{pH} 7 \cdot 5)$, aprotinin $(0 \cdot 1 \mathrm{mg} / \mathrm{ml}), \quad 2 \mathrm{~mm}$-phenylmethanesulfonylfluoride, $10 \mathrm{~mm}-$ sodium orthovanadate, $100 \mathrm{~mm}$-sodium fluoride, $10 \mathrm{~mm}$ sodium pyrophosphate and $10 \mathrm{mm-EDTA}$ ). Two hypothalami were pooled in each vial. Triton $\mathrm{X}-100$ was added to a final concentration of $1 \%$. These extracts were clarified by centrifugation and equal amounts of protein (about $1 \mathrm{mg}$ ) were immunoprecipitated overnight with antibody against either the $5-\mathrm{HT}_{1 \mathrm{~B}}$ receptor or the ST (SC-1460 or SC-1458, respectively; Santa Cruz Biotechnology, Santa Cruz, CA, USA) and resolved in $8 \%$ SDS-PAGE. The $5-\mathrm{HT}_{2 \mathrm{C}}$ receptor protein was determined in total extracts of hypothalamus (160 $\mu \mathrm{g}$ protein), which were directly applied to $10 \%$ SDS-PAGE after extraction.

In all cases, the resolved proteins were transferred to nitrocellulose membranes and probed with the primary antibody against $5-\mathrm{HT}_{1 \mathrm{~B}}$, ST or 5-HT $2 \mathrm{C}$ (SC-15081). All membranes were then incubated with anti-goat secondary antibody conjugated with horseradish peroxidase (A9452; Sigma, St Louis, MO, USA). The detection was performed by chemiluminescence (ECL reagent; Amersham Biosciences, Piscataway, NJ, USA) and quantitative analysis was performed with Scion Image software (Scion Corporation, Frederick, MD, USA).

\section{Statistical analysis}

The results are expressed as means with their standard errors. Basal levels of 5-HT and 5-HIAA were expressed as their absolute dialysate content. A mean baseline level (100\% value) was obtained by averaging the three samples collected just before the introduction of food and the subsequent data were expressed as percentage of the mean baseline level. The microdialysis data were submitted to ANOVA for repeated measures followed by Duncan's test ${ }^{(25)}$, for comparisons among the samples collected throughout the experimental period, in the same group. For comparisons between correspondent samples from the control and restricted groups, the independent Student's $t$ test was used. The area under the curve relating serotonin to time was calculated by the trapezoidal rule.

The other comparisons between the control and restricted groups were performed by the independent Student's $t$ test. The same test was used to compare food intake between vehicle-treated and serotonin-treated rats. Significance was set at $P<0 \cdot 05$.

\section{Results}

As shown in Table 1, the body weight of the control and restricted rats was similar but body fat was significantly higher in the restricted than in the control animals.

As shown in Table 2, basal levels of 5-HT and 5-HIAA in VMH microdialysates were similar between the control and restricted groups.

Figure 1(a) shows the six $20 \mathrm{~min}$ food intakes of the control and restricted groups during collection of VMH microdialysates. Both groups ate the most part of the food in the first $20 \mathrm{~min}$ interval that followed food presentation, with the restricted group eating an amount significantly higher (90\%) than that eaten by the control rats $(P=0 \cdot 020)$. Figure $1(b)$ shows that the intake of food significantly stimulated serotonin levels in $\mathrm{VMH}$ microdialysates in the control $\left(F_{(5,36)}=3 \cdot 55\right.$; $P=0.018)$ and restricted $\left(F_{(5,36)}=3.09 ; \quad P=0.036\right)$ rats. In both groups, serotonin levels showed a progressive increase until the third $20 \mathrm{~min}$ microdialysate sample collected after food presentation. The increase was significantly more pronounced in the restricted than in the control rats in sample 1 $(P=0 \cdot 04)$. From sample 3 to sample 6 , the levels declined in the control group, returning to values similar to baseline. On the other hand, in the restricted group the levels remained significantly elevated, with no decline being apparent until the end of the experimental period. The area under the 
Table 1. Body weight and percentage body fat of control and restricted rats

(Mean values with their standard errors for six rats from three litters)

\begin{tabular}{lccllll}
\hline & \multicolumn{2}{c}{ Body weight $(\mathrm{g})$} & & \multicolumn{2}{c}{ Body fat (\%) } \\
\cline { 2 - 3 } Group & Mean & SE & & Mean & SE \\
\hline Control & 201 & 7 & & 7.7 & 0.7 \\
Restricted & 199 & 6 & & 11.3 & 0.4 \\
Two-sided $P$ values* & \multicolumn{2}{c}{0.95} & & & \multicolumn{2}{c}{0.004} \\
\hline
\end{tabular}

${ }^{\star}$ Estimated by Student's $t$ test.

curve relating serotonin to time was 173 (SE 15) in the control rats and 198 (SE 17) $(P=0 \cdot 14)$ in the restricted rats for the $120 \mathrm{~min}$ after food presentation. In either the control or restricted rats, the levels of 5-HIAA in the VMH microdialysates failed to change significantly (data not shown).

In the control rats, an intracerebroventricular injection of serotonin caused a significant inhibition of $24 \mathrm{~h}$ food intake, in comparison with the intracerebroventricular injection of vehicle $(P=0 \cdot 04)$. On the contrary, the injection of serotonin failed to significantly inhibit feeding in the restricted rats, as the intake was similar to that seen after vehicle injection $(P=0 \cdot 18)$ (Fig. 2).

The Western blot analysis of hypothalamic immunoprecipitates identified the bands corresponding to the ST and 5-HT receptor proteins with $75 \mathrm{kDa}$ and $48 \mathrm{kDa}$, respectively. The levels of the ST protein were slightly $(36 \%)$ but significantly $(P=0.03)$ increased in the hypothalamus of the restricted rats, in comparison with the control rats (Fig. 3 (a)). Hypothalamic levels of the $5-\mathrm{HT}_{1 \mathrm{~B}}$ receptor subtype were $80 \%$ higher in the restricted than in the control females $(P=0.01$; Fig. $3(\mathrm{~b}))$. The $5-\mathrm{HT}_{2 \mathrm{C}}$ receptor protein, identified in the total extracts with $58 \mathrm{kDa}$, showed a $28 \%$ non-significant $(P=0 \cdot 07)$ decrease in the hypothalamus of the restricted rats, in relation to the control ones (Fig. 3 (c)).

\section{Discussion}

Data in the literature indicate that intra-uterine undernutrition may lead to disturbances of appetite and energy homeostasis regulation and adulthood obesity ${ }^{(3,15)}$. We have previously shown that 4-month-old female rats whose dams were undernourished during weeks 1 and 2 of pregnancy had low birth weight and developed non-hyperphagic obesity ${ }^{(16)}$. This

Table 2. Mean baseline levels of 5-hydroxytryptamine (5-HT) and 5-hydroxyindoleacetic acid (5-HIAA) of control and restricted rats

(Mean values with their standard errors for six control and seven restricted rats from three to four litters)

\begin{tabular}{|c|c|c|c|c|}
\hline \multirow[b]{3}{*}{ Group } & \multicolumn{4}{|c|}{ Basal microdialysate levels } \\
\hline & \multicolumn{2}{|c|}{ 5-HT (pg/30 $\mu \mathrm{l})$} & \multicolumn{2}{|c|}{ 5-HIAA (ng/30 $\mu \mathrm{l})$} \\
\hline & Mean & SE & Mean & SE \\
\hline Control & 2.46 & 0.45 & 0.56 & 0.11 \\
\hline Restricted & $2 \cdot 88$ & 1.03 & 0.69 & 0.17 \\
\hline Two-sided $P$ values ${ }^{*}$ & \multicolumn{2}{|c|}{0.69} & \multicolumn{2}{|c|}{0.59} \\
\hline
\end{tabular}

*Estimated by Student's $t$ test.
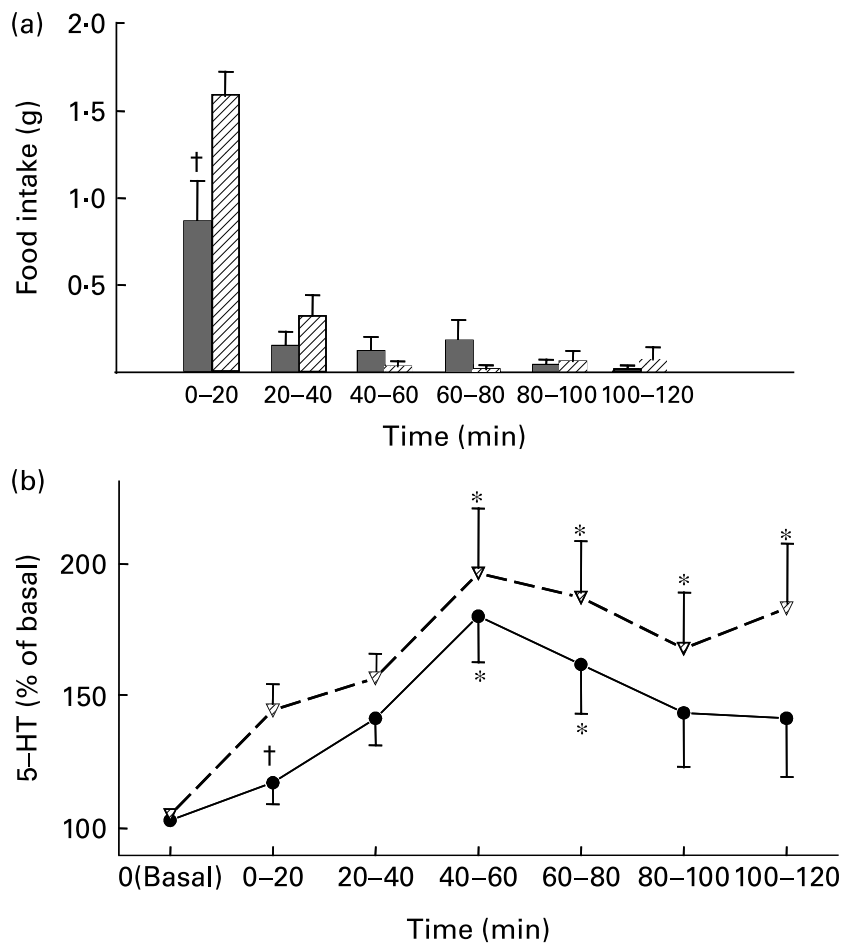

Fig. 1. (a) Food intake during the six consecutive 20 min periods after food presentation to control $(\square)$ and restricted (何) rats. (b) 5-Hydroxytryptamine (5-HT) levels in 20 min ventromedial hypothalamus microdialysates collected before (basal) and up to $120 \mathrm{~min}$ after the presentation of food to control $(-\bullet-)$ and restricted $\left(-\nabla^{-}\right)$rats. Values are means for six control and seven restricted rats from three to four litters, with their standard errors represented by vertical bars. * Mean value was significantly different from basal $(P<0.05)$. † Mean value of the restricted rats was significantly different from that of the control rats $(P<0.05)$.

indicated that a high energetic efficiency contributed to the excess fat deposition, agreeing with the report of a low brown adipose tissue activity in rats exposed to intra-uterine undernutrition $^{(26)}$.

With the purpose of understanding the participation of disturbances in the hypothalamic systems that control energy

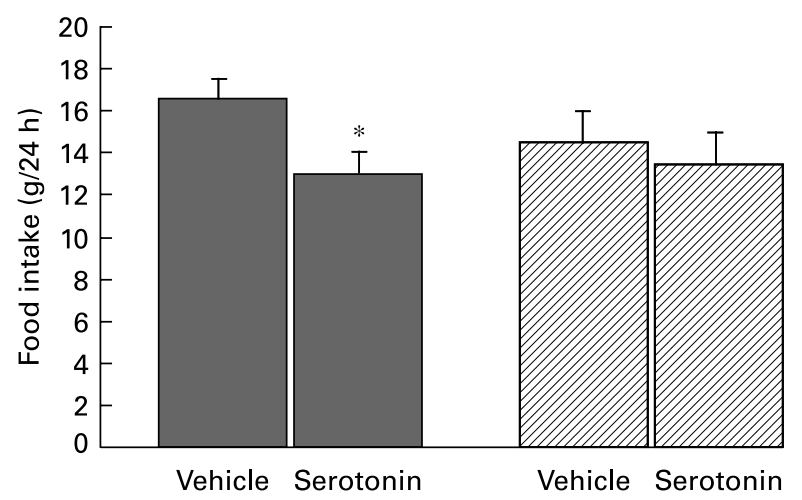

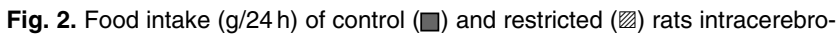
ventricularly treated with either vehicle or $300 \mu \mathrm{g}$ serotonin. Values are means for eight control and sixteen restricted rats for each treatment from four to eight litters, with their standard errors represented by vertical bars. * Mean value was significantly different from that of the vehicle treatment $(P<0.05)$. 

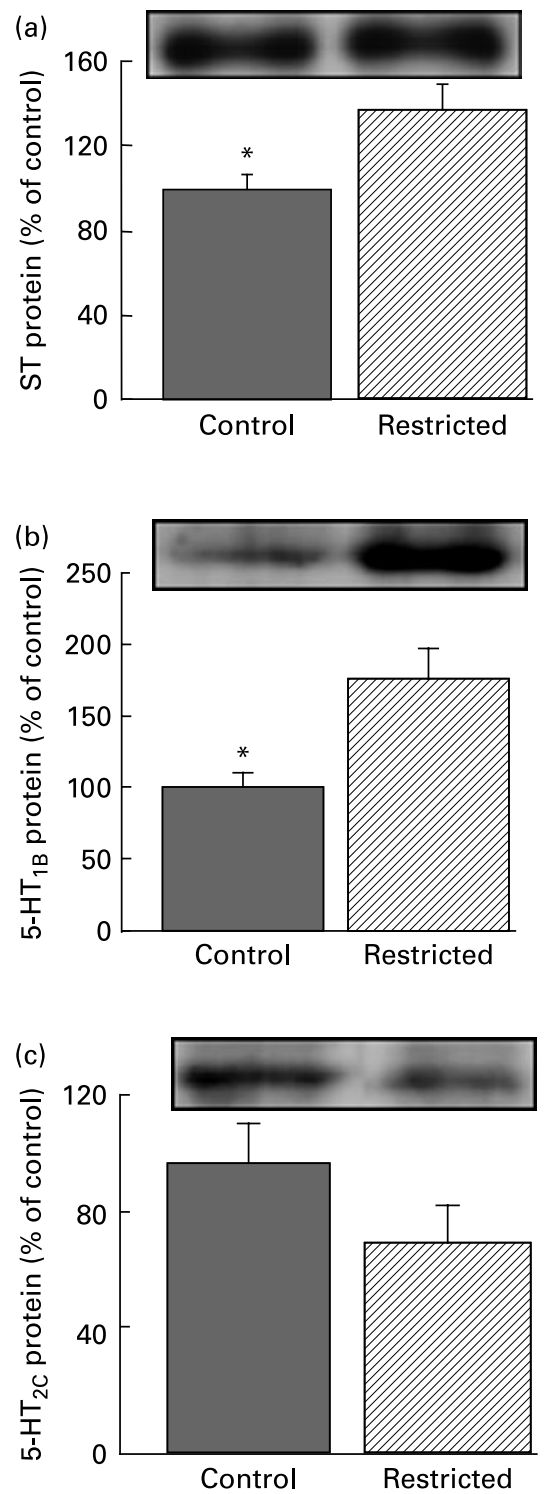

Fig. 3. Hypothalamic protein levels of (a) the serotonin transporter (ST; $n 6$ ), (b) 5-hydroxytryptamine (5-HT) ${ }_{1 \mathrm{~B}}$ receptor $(n 7-9)$ and (c) $5-\mathrm{HT}_{2 \mathrm{C}}$ receptor $(n 7)$ in control and restricted rats. Data are are expressed in densitometric arbitrary units. Values are means, with their standard errors represented by vertical bars. ${ }^{*}$ Mean value was significantly different from that of the restricted rats $(P<0.05)$.

homeostasis on the establishment of the normophagic obesity in animals malnourished in utero, we have previously examined the action of insulin. We demonstrated impairment of insulininduced hypophagia and blunting of insulin signalling activation in the hypothalamus of restricted females. Additionally, we found their circulating leptin levels to be increased ${ }^{(16)}$. Other authors have described hypothalamic resistance to leptin in adult rats born from mothers protein-energy restricted during lactation $^{(27)}$. Those data indicated that, despite the observed normophagia, multiple aspects of the central control of energy homeostasis might be compromised in adult female rats prenatally exposed to undernutrition. The present study was aimed at further examining this control, focusing on aspects of the hypothalamic serotonergic function. An important consideration to the rationale of the present study was that both hyperphagia and hypometabolism, common disturbances present in different obesity syndromes, could be consequences of serotonergic dysfunction, as serotonin inhibits food intake and stimulates thermogenesis ${ }^{(2,4,28)}$. Moreover, although pharmacological activation of central serotonin has long been used as a tool in the treatment of obesity, not much is known about the actual status of the hypothalamic serotonergic system in obese animals and humans.

The present brain microdialysis experiments showed that, during food ingestion, serotonin levels in microdialysates of the medial hypothalamus increased earlier and remained elevated longer in the restricted rats when compared with the control rats. Moreover, the present finding of increased levels of the ST protein is compatible with an elevated hypothalamic turnover of the amine. These observations are in agreement with the reports of increased hippocampal serotonin release in response to raphe electrical stimulation and of elevated free plasma L-tryptophan and brain tryptophan hydroxylase activity in rats prenatally protein malnourished ${ }^{(29,30)}$.

Exacerbation of the serotonergic response to food has been previously found in hyperphagic obese rats and suggested to reflect a compensatory mechanism aimed at overcoming a putative functional resistance to the released amine ${ }^{(6,10,11)}$. In contrast, in a model of non-hyperphagic and hypometabolic obesity, induced by neonatal treatment with the excitotoxin monosodium glutamate ${ }^{(31)}$, we have previously demonstrated that the pattern of serotonin release in the lateral hypothalamus, as stimulated by the ingestion of food, was similar to that seen in normal rats ${ }^{(6)}$. Serotonin released at hypothalamic sites during food intake plays a relevant part in the physiological response directed towards satiety and also contributes to thermogenesis ${ }^{(5-10)}$

To ascertain whether a functional resistance to serotonin was present in the restricted females, we measured the effect, on the $24 \mathrm{~h}$ food intake, of an intracerebroventricular injection of $300 \mu \mathrm{g}$ serotonin. The findings confirmed the suspected impairment of serotonin action in the restricted rats, by showing that serotonin reduced food intake in the control rats while it failed to significantly inhibit ingestion in the restricted ones. A lower dose of serotonin $(200 \mu \mathrm{g})$ was ineffective in inhibiting intake in either group (data not shown). These observations reinforce the probability that the excess amount of serotonin released in response to feeding, as observed in the present microdialysis experiments, was developed as a compensation for the impaired ability of the amine to properly induce its biological effect.

The $5-\mathrm{HT}_{1 \mathrm{~B}}$ and $5-\mathrm{HT}_{2 \mathrm{C}}$ receptor subtypes are important mediators of serotonin hypophagia but it is not completely known how they interact to support this serotonergic function. They have been recently shown to, respectively, inhibit neuropeptide Y/Agouti-related peptide neurons and stimulate proopiomelanocortin neurons in the arcuate nucleus ${ }^{(32)} \cdot 5-\mathrm{HT}_{1 \mathrm{~B}}$ has been shown to be hyper-responsive to agonist stimulation in $5-\mathrm{HT}_{2 \mathrm{C}}$ knockout mice, demonstrating that these serotonergic receptors are able to accomplish compensatory adaptations $^{(33)}$.

Since the blunting of serotonin-induced hypophagia could be due to diminished receptor density, we measured the hypothalamic amount of these receptors. While 5-HT $2 \mathrm{C}$ levels were decreased, although non-significantly, those of the $5-\mathrm{HT}_{1 \mathrm{~B}}$ 
receptor were increased in the restricted rats. This observation does point to a compensatory adaptation, potentially able to overcome serotonin inefficacy. We also found a significantly higher amount of the ST protein in the hypothalamus of the restricted group, a finding compatible with the high local activity of the system, indicated by the exacerbated release elicited by a meal. It is interesting to note that increased 5-HT ${ }_{1 \mathrm{~B}}$ and ST binding sites have been described in the hypothalamus of rats made obese by cafeteria feeding ${ }^{(34)}$.

It is possible that either an impaired interaction of serotonin with its receptors or a defective stimulation of the transducing pathways after receptor binding was involved in the altered ability of the neurotransmitter to reduce food intake. Experiments specially designed to explore these aspects will help ascertain to what extent each of these putative abnormalities contributed to the alterations in serotonin action observed in the restricted rats.

The serotonergic system has been shown to be influenced by oestrogen hormones ${ }^{(35)}$ and we have reported sex differences in the late effects of intra-uterine malnutrition, with obesity and hypothalamic insulin resistance having developed in the female but not in the male offspring ${ }^{(6)}$. Results from our laboratory (FLC Sardinha, MM Telles, KT Albuquerque, LM Oyama, CMO Nascimento and EB Ribeiro, unpublished results) demonstrated that, unlike the females, the male restricted offspring had a normal hypophagic response to serotonin. Thus, although the relevance of the ovarian hormones to the present findings was not specifically examined, as this aspect was beyond the scope of the present study, they are likely to have played a role.

In newborn and infant animals and humans, there are reports of alterations in the central serotonergic system, induced by intra-uterine or early life malnutrition, which could lead to serotonin-related disorders in later life ${ }^{(19-21)}$. In the present experiments, we were able to demonstrate that female rats exposed to intra-uterine malnutrition retain, as adults, abnormalities in central serotonin physiology, indicating a programming effect of the early undernutrition upon the brain serotonergic system. The present data reinforce our previous demonstration that the brain neural network regulating appetite and energy homeostasis is affected by the exposure to a mild nutritional deficit, confined in a very precocious period of intra-uterine life ${ }^{(16)}$.

It is noteworthy that compensatory responses developed to counteract the functional inefficacy of 5-HT, which included increased capacity to release serotonin and increased receptor density. Acting in conjunction, these adaptive responses were probably relevant towards the establishment of a normophagic phenotype. However, the presence of increased body adiposity indicates that the regulation of energy balance was abnormal in the restricted animals and it cannot be ruled out that impairment of the serotonergic component of energy expenditure contributed to it.

\section{Acknowledgements}

The present study was supported by a grant from the National Council for Scientific and Technological Development (Conselho Nacional de Desenvolvimento Científico e Tecnológico; CNPq). L. C. J. P., F. L. C. S. and M. M. T. were recipients of fellowships from the Coordination for the
Enhancement of Higher Education Personnel (Coordenação de Aperfeiçoamento de Pessoal de Nível Superior; CAPES). R. B. G. was recipient of a fellowship from the State of São Paulo Research Foundation (Fundação de Amparo à Pesquisa do Estado de São Paulo; FAPESP). The laboratories of L. M. O., C. M. O. N., O. F. P. S. and E. B. R. were supported by research grants from $\mathrm{CNPq}$ and FAPESP.

The experiments of the present study were performed by L. C. J. P., F. L. C. S., M. M. T., R. B. G., K. T. A., I. S. A. and L. M. O. All authors contributed to the discussion and writing of the paper. L. C. J. P. and F. L. C. S. contributed equally to the study.

The authors declare no conflict of interest.

\section{References}

1. Saper CB, Chou TC \& Elmquist JK (2002) The need to feed: homeostatic and hedonic control of eating. Neuron 36, 199-211.

2. Ribeiro EB, Telles MM, Oyama LM, Silveira VLF \& Nascimento CMO (2005) Hypothalamic serotonin in the control of food intake: physiological interactions and effect of obesity. In Focus on Nutrition Research, pp. 121-148 [TP Starks, editor]. New York: Nova Science Publishers.

3. Cripps RL, Martin-Gronert MS \& Ozanne SE (2005) Fetal and perinatal programming of appetite. Clin Sci 109, 1-11.

4. Meguid MM, Fetissov SO, Varma M, Sato T, Zhang L \& RossiFanelli F (2000) Hypothalamic dopamine and serotonin in the regulation of food intake. Nutrition 16, 843-857.

5. Schwartz DH, Hernandez L \& Hoebel BG (1990) Serotonin release in lateral and medial hypothalamus during feeding and its anticipation. Brain Res Bull 25, 797-802.

6. Mori RCT, Guimarães RB, Nascimento CMO \& Ribeiro EB (1999) Lateral hypothalamic serotonergic responsiveness to food intake in rat obesity as measured by microdialysis. Can $J$ Physiol Pharmacol 77, 286-292.

7. Mori RCT, Telles MM, Guimarães RB, Novo NF, Juliano Y, Nascimento CMO \& Ribeiro EB (2004) Feeding induced by increasing doses of neuropeptide Y: dual effect on hypothalamic serotonin release in normal rats. Nutr Neurosci 7, 235-239.

8. Guimarães RB, Telles MM, Coelho VBO, Mori RCT, Nascimento CMO \& Ribeiro EB (2002) Adrenalectomy abolishes the food-induced hypothalamic serotonin release in both normal and monosodium glutamate-obese rats. Brain Res Bull 58, 363-369.

9. Telles MM, Guimarães RB \& Ribeiro EB (2003) Effect of leptin on the acute feeding-induced hypothalamic serotonergic stimulation in normal rats. Reg Pep 115, 11-18.

10. De Fanti BA, Hamilton JS \& Horwitz BA (2001) Meal-induced changes in extracellular 5-HT in medial hypothalamus of lean $(\mathrm{Fa} / \mathrm{Fa})$ and obese ( $\mathrm{fa} / \mathrm{fa})$ Zucker rats. Brain Res 902, 164-170.

11. Orosco M, Rouch C, Meile MJ \& Nicolaidis S (1995) Spontaneous feeding-related changes in rostromedial hypotalamus of the obese Zucker rat: a microdialysis study. Physiol Behav 57, 1103-1106.

12. Meguid MM, Fetissov SO, Blaha V \& Yang ZJ (2000) Dopamine and serotonin release is related to feeding status in obese and lean Zucker rats. Neuroreport 11, 2069-2072.

13. Hainer V, Kabrnova K, Aldhoon B, Kunesova M \& Wagenknecht $M$ (2006) Serotonin and norepinephrine reuptake inhibition and eating behavior. Ann N Y Acad Sci 1083, 252-269.

14. Halford JCG, Harrold JA, Boyland EJ, Lawton CL \& Blundell JE (2007) Serotonergic drugs: effects on appetite expression and use for the treatment of obesity. Drugs 67, 27-55.

15. Taylor PD \& Poston L (2007) Developmental programming of obesity in mammals. Exp Physiol 92, 287-298. 
16. Sardinha FLC, Telles MM, Albuquerque KT, Oyama LM, Guimarães PAMP, Santos OFP \& Ribeiro EB (2006) Gender difference in the effect of intrauterine malnutrition on the central anorexigenic action of insulin in adult rats. Nutrition 22, 1152-1161.

17. Gehlert DR, Thompson LK, Hemrick-Luecke SK \& Shaw J (2008) Monoaminergic compensation in the neuropeptide $\mathrm{Y}$ deficient mouse brain. Neuropeptides 42, 367-375.

18. Chen JC, Turiak G, Galler J \& Volicer L (1997) Postnatal changes of brain monoamine levels in prenatally malnourished and control rats. Int J Dev Neurosci 15, 257-263.

19. Kehoe P, Mallison K, Bronzino J \& McCormick CM (2001) Effects of prenatal protein malnutrition and neonatal stress on CNS responsiveness. Dev Brain Res 132, 23-31.

20. Manjarrez G, Manuel AL, Mercado CR \& Hernandez RJ (2003) Serotonergic receptors in brain of in utero undernourished rats. Int J Dev Neurosci 21, 283-289.

21. Manjarrez G, Cisneros I, Herrera R, Vazquez F, Robles A \& Hernandez J (2005) Prenatal impairment of brain serotonergic transmission in infants. J Pediatr 147, 592-596.

22. Leshner AI, Litwin VA \& Squibb RL (1972) A simple method for carcass analysis. Anal Biochem 9, 281-282.

23. Stansbie D, Browsey RW, Crettaz M \& Demton RM (1976) Acute effects in vivo of anti-insulin serum on rates of fatty acids synthesis and activities of acetyl-coenzyme A carboxylase and pyruvate dehydrogenase in liver and epididymal adipose tissue of fed rats. Biochem J 160, 413-416.

24. Paxinos D \& Watson C (1986) The Rat Brain in Stereotaxic Coordinates. New York: Academic Press.

25. Duncan DB (1955) Multiple range and multiple $F$ test. Biometrics 11, 1-42.

26. Anguita RM, Sigulem DM \& Sawaya AL (1993) Intrauterine food restriction is associated with obesity in young rats. $J$ Nutr 123, $1421-1428$.
27. Passos MCF, Vicente LL, Lisboa PC \& Moura EG (2004) Absence of anorectic effect to acute peripheral leptin treatment in adult animals whose mothers were malnourished during lactation. Horm Metab Res 36, 625-629.

28. Rothwell NJ \& Stock MJ (1987) Effect of diet and fenfluramine on thermogenesis in the rat: possible involvement of serotonergic mechanisms. Int J Obes 11, 319-324.

29. Mokler DJ, Bronzino JD, Galler JR \& Morgane PJ (1999) The effects of median raphé electrical stimulation on serotonin release in the dorsal hippocampal formation of prenatally protein malnourished rats. Brain Res 838, 95-103.

30. Manjarrez G, Chagoya G \& Hernandez J (1988) Perinatal brain serotonin metabolism in rats malnourished in utero. Biol Neonate 54, 232-240.

31. Ribeiro EB, Nascimento CMO, Andrade IS, Hirata AE \& Dolnikoff MS (1997) Hormonal and metabolic adaptations to fasting in monosodium glutamate obese rats. J Comp Physiol B 167, 430-437.

32. Heisler LK, Jobst EE, Sutton GM, et al. (2006) Serotonin reciprocally regulates melanocortin neurons to modulate food intake. Neuron 51, 239-249.

33. De Vry J \& Schreiber R (2000) Effects of selected serotonin 5-HT(1) and 5-HT(2) receptor agonists on feeding behavior: possible mecanisms of action. Neurosci Biobehav Rev 24, 341-353.

34. Park S, Harrold JA, Widdowson PS \& Williams G (1999) Increased binding at 5-HT1A, $5-\mathrm{HT}_{1 \mathrm{~B}}$, and $5-\mathrm{HT}_{2 \mathrm{~A}}$ receptors and 5-HT transporters in diet-induced obese rats. Brain Res 847, 90-97.

35. Raap DK, DonCarlos LL, Garcia F, Zhang Y, Muma NA, Battaglia G \& Van de Kar LD (2002) Ovariectomy-induced increases in hypothalamic serotonin-1a receptor function in rats are prevented by estradiol. Neuroendocrinology 76, 348-356. 